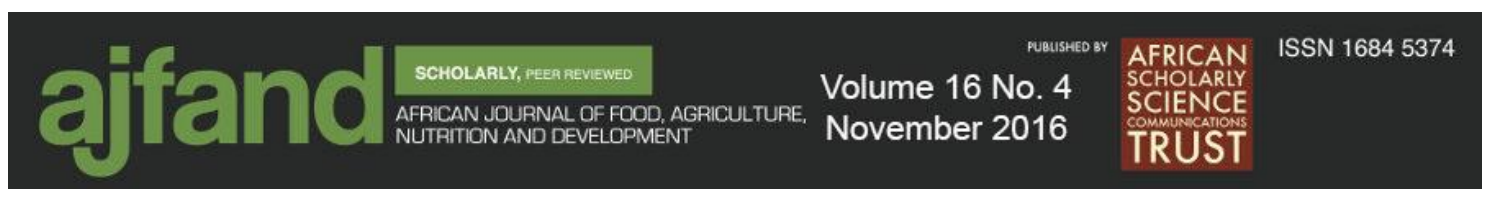

DOI: 10.18697/ajfand.76.15840

\title{
PROGRESS IN NUTRITION RELATED MILLENNIUM DEVELOPMENT GOALS IN UGANDA BEFORE ADOPTION OF POST-2015 DEVELOPMENT AGENDA: REVIEW OF GOALS 1, 2 AND 4
}

\author{
Balikuddembe $\mathrm{KJ}^{1 \& 2^{*}}$, Hosseinzadeh-Attar $\mathrm{MJ}^{3}$ and A Ardalan ${ }^{4}$
}

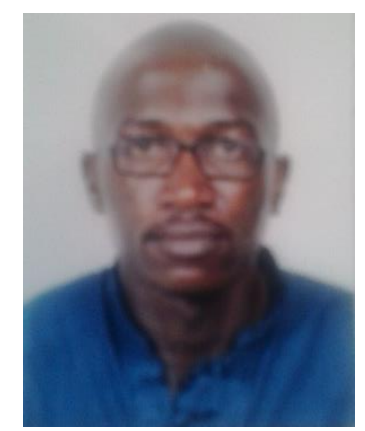

Joseph Balikuddembe Kimuli

*Corresponding author email: jbalikuddembe.k@gmail.com

${ }^{1}$ East African Center for Disaster Health and Humanitarian Research, Kampala, Uganda

${ }^{2}$ Department of Disaster Public Health, School of Public Health - Tehran University of Medical Sciences, Tehran Iran; Tehran University of Medical Sciences - International Campus, Tehran Iran

${ }^{3}$ Department of Clinical Nutrition, School of Nutritional Sciences and Dietetics - Tehran University of Medical Science, Tehran, Iran

${ }^{4}$ Department of Disaster Public Health, School of Public Health -Tehran University of Medical Sciences, Tehran, Iran; National Institute of Health Research, Tehran University of Medical Sciences, Tehran, Iran; Harvard Humanitarian Initiative, Harvard University, Cambridge, USA 


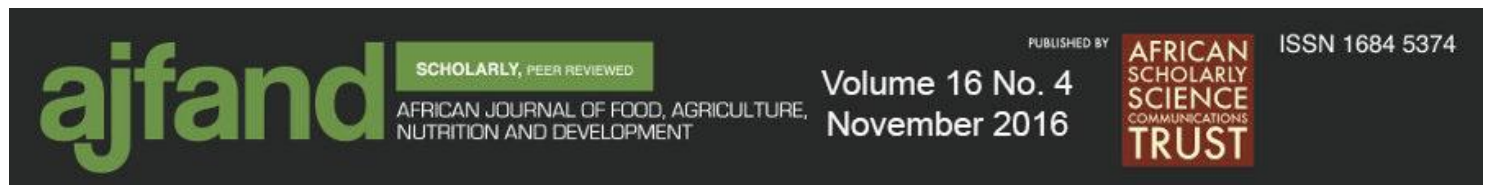

\begin{abstract}
Promulgation of Millennium Development Goals (MDG) in year 2000 gave hope to the world that common interests and challenges such as poverty and hunger, education, gender equality and women empowerment, child mortality and maternal health, diseases such as, HIV/AIDS, malaria, environmental sustainability, as well as global partnerships that were affecting the world could, respectively, be prioritized and responded to within a timeframe of the year 2001 to 2015. In this case, the developing countries like Uganda were accorded great attention. Nutrition has been at the forefront of the MDG implementation as one of the daunting challenges affecting developing countries. This paper is based on a narrative review of quantitative and qualitative data aimed at establishing the progress Uganda made towards achieving the three nutrition related MDG (1, 2 and 4). A timeframe of 2001 when the goals were officially launched up to the deadline of $31^{\text {st }}$ December 2015 and the adoption of the Post-2015 Development Agenda was considered. The majority of Low and Middle Income Developing Countries (LMIDCS) failed to make substantial progress in achieving most of the goals, including the nutrition related goals. Uganda only achieved MDG one - target 1.A indicator of halving a proportion of people living below less than $\$ 1.25$ a day. To some extent, this helped in alleviating poverty, creating jobs, and generating income and saving and other opportunities which are indeed catalysts to human development and socioeconomic wellbeing. Unfortunately, Uganda missed achieving the rest of the nutrition related MDG. They included: reducing underweight children under five years (MDG 1.8), increasing net enrollment of boys and girls in primary education (MDG 2.1), increasing proportion of pupils starting grade one to last primary grade (MDG 2.2), reducing child mortality rate per 1,000 live births (MDG 4.1) and reducing infant mortality rate per 1,000 live births (MDG 4.2). However, the hope at this particular moment ought to be directed towards tracking and achieving goals in the Post-2015 Development Agenda whose aim is mainly to build on the progress of the MDG.
\end{abstract}

Key words: Nutrition, Millennium Development Goals, Post-Development Agenda, Uganda 


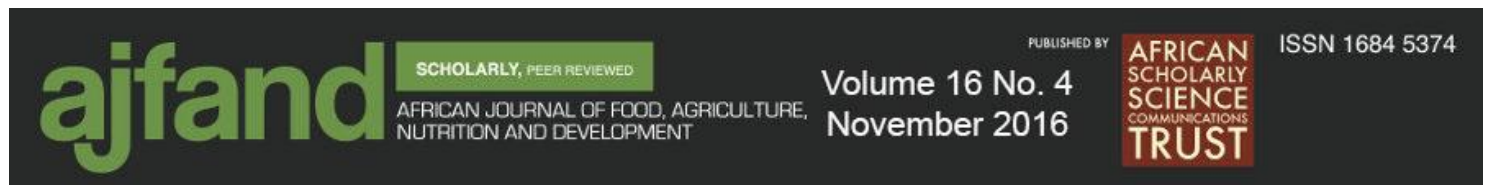

\section{INTRODUCTION}

At the turn of last century, the United Nations (UN) member states committed themselves to ushering common interests forward and responding to challenges. From $6^{\text {th }}$ to $8^{\text {th }}$ September 2000, a summit convening 147 Heads of State and Government and 189 Member States in total, the largest-ever gathering of world leaders met and committed to a number of matters [1]. Subsequently, the A/55/L.2 resolution was unanimously adopted henceforth promulgating what came to be known as the United Nations Millennium Declaration (UNMD) [2]. The Declaration was summarized into eight (8) Millennium Development Goals (MDG): (1) eradicating extreme poverty and hunger; (2) achieving universal primary education; (3) promoting gender equality and empowering women; (4) reducing child mortality; (5) improving maternal health; (6) combating HIV/AIDS, malaria and other diseases; (7) ensuring environmental sustainability; and (8) developing a global partnership for development [3]. The 8 goals were adopted and enclosed along with 20 targets and 60 plus indicators as a pathway to achieving them. In light of this, the goals became the world's biggest promise - a global agreement to reduce poverty and human deprivation at historically unprecedented rates through collaborative action [4].

The MDG received worldwide attention after their promulgation. However, the deadline of achieving them passed on $31^{\text {st }}$ December 2015 and thereafter the already proposed Post-2015 Development Agenda commenced. The latter stipulates 17 Sustainable Development Goals aimed at building on the progress so far reached with the eight MDG that the world committed to achieve by 2015 [5]. Therefore, at this juncture when the implementation of Post-2015 Development Agenda has just began, it is right and fitting to filter the progress which was made in achieving some of the MDG. This deserves attention particularly for the developing countries in sub- Sahara Africa (SSA) which were pessimistically predicted to fail in achieving the MDG by a large margin in 2015 [6-7]. It is noted, however, that this seems to have been premised on the ambivalent agenda of some powerful global actors against the interests of low and middle income developing countries (LMICS).

Uganda shared the same problems with all LMICS in achieving the MDG despite realizing an astounding economic growth and development in the recent years. Its rate of gross domestic product (GDP) has been rebounding between the rate of $5.1 \%-7.8 \%$ compared to $3.1 \%$ in 1985 and 1990 [8-9]. Achieving the nutrition-related goals has been critical. This is because evidence shows that good nutrition is a prerequisite for human development, socioeconomic well-being and a foundation for sustainable development [10-11]. Additionally, nutrition health and security are underpinned as linchpins and enablers for achieving some if not all the MDG [12-15]. Against this backdrop, the present paper explores Uganda's progress so far registered in achieving the nutritionrelated MDG 1, 2, and 4 before the dawn of $31^{\text {st }}$ December 2015 deadline.

\section{METHOD}

This paper is a narrative review based on wide analysis of quantitative and qualitative data. Two indicators as shown in table 1 for each goal stipulated for monitoring their progress were selected. Data sources were reports or official documents cross-cutting 


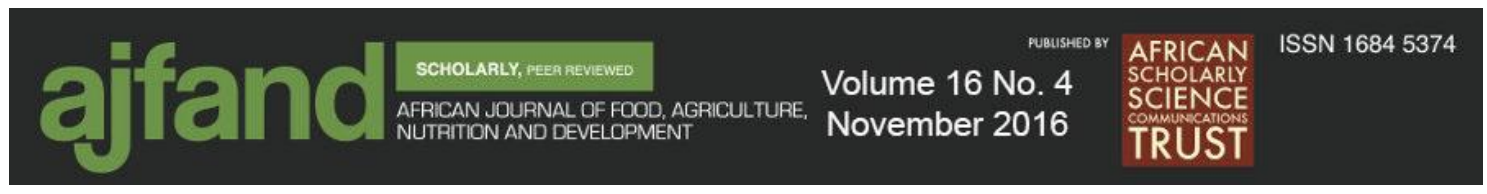

from the Uganda government and international institutions. A timeframe between 2001 and 2015 was focused on as follows: in the former it is when the official implementation of MDG commenced while in the latter it is when achieving the goals expired. Some reports and associated documents were freely retrieved and downloaded. Using the Tehran University of Medical Sciences Digital Library, nutrition articles related to the topic from seven online databases were also searched and retrieved: PLoS one, Google Scholar, Pub Med, Web of Science, Springer, MEDLINE, and National Center for Biotechnology Information (NCBI).

The search keywords were: ("nutrition" OR "malnutrition" OR "millennium development goals" OR "post-2015 millennium development goals" OR "Uganda") AND (progress report OR "nutrition" OR "millennium development goals" OR "Uganda"). They were interchanged with each other. The search was augmented by exploring references or bibliographies of the first search results. In this case, any relevant references were found manually using the Google search engine in order to retrieve further relevant data and information.

Five-year time intervals were used; 2001 - 2005, 2006 - 2010, and 2011 - 2015. It should be noted that 2015 data were not all available. The five-year interval was deemed to be worthy in evaluating the progress of achieving the MDG whereby, each period was compared to one another.

Predefined inclusion and exclusion criteria guided the entire search and review processes. The information and data which were eligible for review had to meet these conditions: (a) officially published and in English language, (b) relating to the study topic and freely accessible and retrievable, (c) published between 2001 and 2015. On the other hand, information and data were excluded if they: (a) did not show any relationship to the topic or keywords, (b) were not officially published, or (c) were published in other languages not English. The search and review processes underwent three steps: 1) the titles and keywords of all the searched reports and documents were critically observed in order to ensure that that they related to the topic; 2) their foreword, executive summaries or abstracts were screened; and 3) the full texts of all qualifying reports and documents were studied in-depth.

More than 60 official reports and related documents published within and outside Uganda by different institutions were retrieved. However, 15 of them were selected for a critical and full-scale review after they were assessed to be relevant to the topic. Varying online statistical data were also retrieved. Results of quantitative data on Uganda's progress in fostering the MDG 1, 2 and 4 are presented in figure 1. 


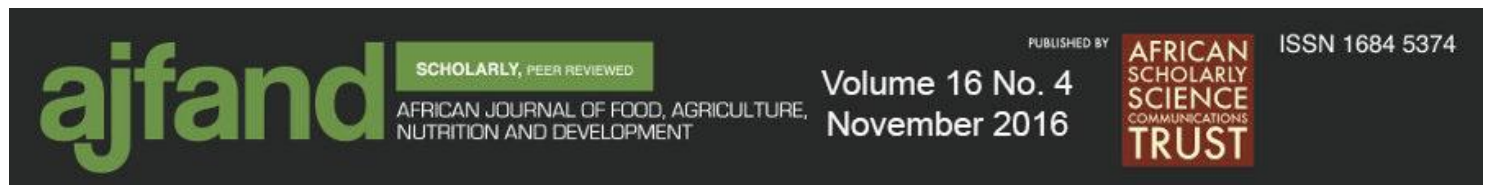

\section{Quality Control}

To ensure validity of quantitative data explored, it was rigorously cross-checked and matched using at least three different sources. This was to ensure that the numbers presented were similar or nearly in the same range with each other.

\section{RESULTS}

In 2001 the progress indicators were reported at: $33.8 \%$ proportion of population living below poverty (PPP) $\$ 1.25$ per day (MDG 1.1), $22.8 \%$ underweight children under five years of age (MDG 1.8), 50.9\% net enrollment of both boys and girls in primary education (MDG 2.1), and 14.6\% proportion of pupils starting grade one up to last primary grade (MDG 2.2). For under five child mortality rate (U5MR) (MDG 4.1) and infant mortality rate (IMR) (MDG 4.2) they were reported at 152 and 88 per 1,000 live births, respectively. However, there was a promise that in the course of the later years of MDG implementation some targets could optimistically be reached. Five years later in 2005, a decline happened with MDG 1.1 and MDG 1.8, at $31.0 \%$ and $15.9 \%$, respectively. For MDG 4.1 and MDG 4.2; 137 and 76 per 1,000 live births respectively, were experienced. The net school enrollment increased to $84 \%$ while the proportion in pupils failing to complete up to the last grade reduced to $10.7 \%$. Unfortunately, no target was met in the first five years of MDG implementation.

Ten years down the road of implementing MDG in 2010, a decrease was also realized with MDG 1.1 and MDG 1.8 decreasing to the level of $24.5 \%$ and $13.8 \%$, respectively. The school enrollment declined a bit at $83 \%$ whereas the proportion of pupils failing to complete school reduced to $6 \%$. A decrease in U5MR and IMR was registered at 135 and 70 per 1,000 live births, respectively. On a special note, it is gratifying to mention that for the first time, one target relating to halving the proportion of population living in poverty (PPP) of $<\$ 1.25$ per day was achieved.

As the world was heading towards the $30^{\text {th }}$ December 2015 deadline, the success that Uganda registered with PPP $<\$ 1.25$ was maintained at $25.0 \%$. The $<$ five underweight children stood at $15.9 \%$. Much as the net school enrollment increased to $90 \%$, the proportion of pupils failing to complete last grade unfortunately stood at $16 \%$. The U5MR and IMR were recorded at 90 per 1,000 live births and 54 per 1,000 live births, respectively which were beyond the universal target of 30 per 1,000 live births. 

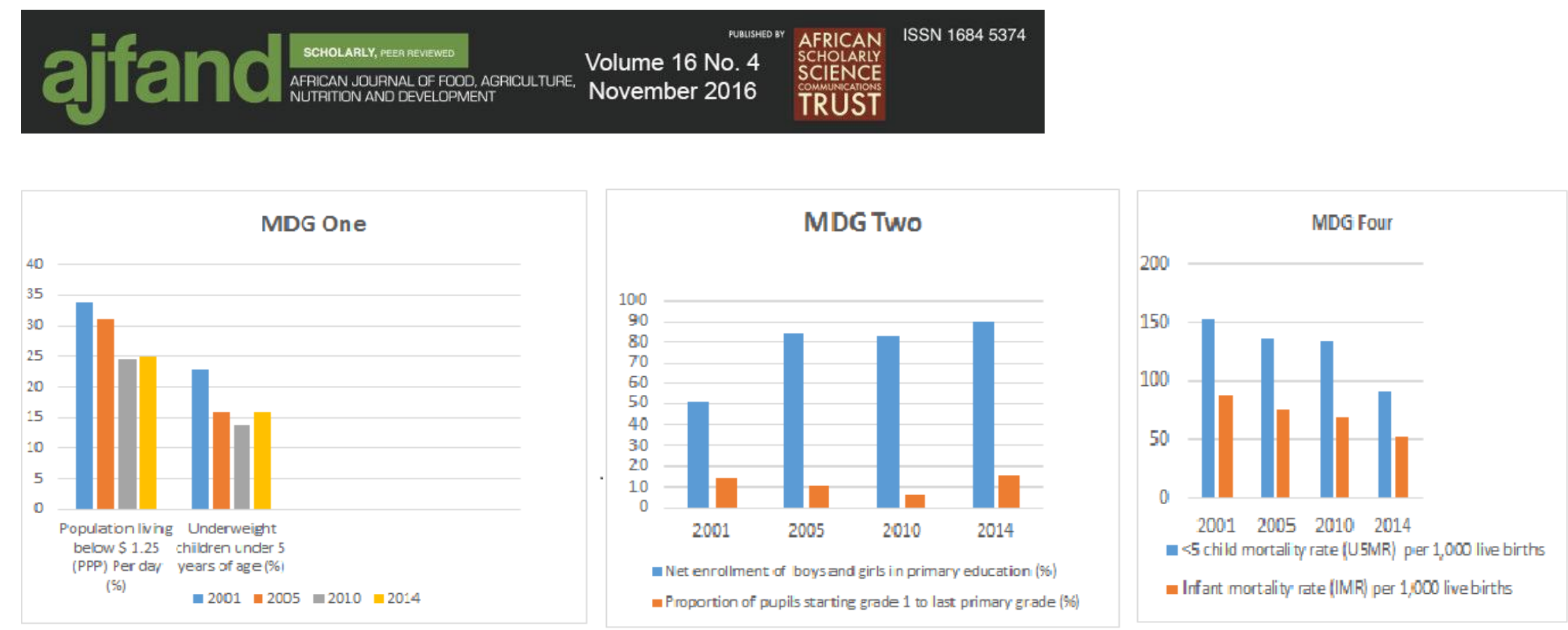

Figure 1: Graphs indicating progress of Millennium Development Goal 1, 2 and 4 indicators in Uganda Source: United Nations Secretary General reports

\section{Acronyms}

MDG: Millennium Development Goal

U5MR: <5 Child Mortality Rate

PPP: Proportion of Population Living below Poverty

IMR: Infant Mortality Rate 


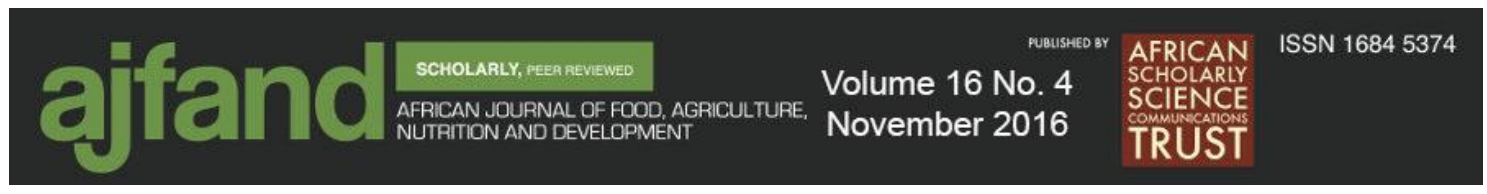

\section{DISCUSSION}

Many developing countries especially in SSA were predicted to fail in achieving any MDG targets and Uganda was no exception. To the contrary, Uganda's robust economic progress had been striking over the years at an average rate of 5.6\% [8-9], leading to the attainment of MDG 1.1 target well before the 2015 deadline. As a result, the poverty-hit population reduced from $33.8 \%$, to $25.0 \%$ between 2001 and 2015, respectively. This success exceeded the Uganda's National Development Plan (NDP) target of $25 \%$ before $2014 / 15$ [16]. It was preceded by the poverty levels falling to $24 \%$ in $2010 / 14$ compared to $56.4 \%$ in 1992/93. Accordingly, this was attributed to the success of Uganda's Poverty Eradication Action Plan (PEAP) 2004/5 - 2007/8 among other factors [17]. The NDP and PEAP aimed at spearheading Uganda's economic growth and development, and alleviating poverty. To achieve this, a number of eradication strategies were lined up alongside some important nutritional undertakings such as nutrition education and advocacy, agricultural seed donation, complementary feeding programmes and others. Thereafter, the Ugandan population subsisting on $<\$ 1.25$ per capita per day was successfully reduced nearly to below $20 \%$ in the first 10 years of MDG implementation. In so happening, not only was the poverty challenge tackled but also income and food security were enhanced contributing to a steady reduction in hunger and under-nutrition especially among the poor.

In view of the afore-indicated data, it was observed that to some extent MDG 1.1 was also accompanied by a slight reduction in the under-five underweight. However, this was not to the expectation of the 2015 target. Its proportion reduced from $22 \%$ to $15.9 \%$ and $13.8 \%$ in 2001, 2005 and 2010, respectively. Unfortunately, the MDG 1.8 slightly rose again to $15.9 \%$ in 2014 compared to $13.8 \%$ in 2010 according to the updated statistics despite having in place the Uganda Nutrition Action Plan (UNAP) 2011- 2016. The latter aimed at scaling-up some nutritional promotion mechanisms such as breastfeeding, complementary feeding, micronutrient (iron and Vitamin A) programmes and food fortification [14]. It should be noted that from time to time some UNAP mechanisms have been correlated with the poverty eradication actions especially those intending to uplift the socioeconomic livelihoods of the most nutritionally vulnerable groups in Uganda. However, Uganda's performance is similar to that of other countries in SSA. Despite a modest reduction in prevalence of underweight children since 1990, it was only SSA region where the number of undernourished children increased from an estimated 27 million to 32 million between 1990 and 2012 [18].

In terms of MDG 2, Universal Primary Education (UPE), Uganda's ongoing progress can be analogously ascertained. In the first instance, the progress of achieving MDG 2.1 was registered as $90 \%$ from 50.9\% in 2001 and MDG 2.2 was commendable. However, despite this success, the country was yet to reach the $100 \%$ primary enrollment MDG target by 2015. To this matter, it is worth reporting that Uganda was one of the first African countries to introduce the UPE [19] in 1997 even before the MDG declaration. As a result, on several occasions it has been a reference model in establishing similar UPE systems in other developing countries since it has been faring quite well in Uganda. To a considerable degree, the UPE in Uganda has increased the basic level of maternal 
education which in turn influences nutritional health and then improves the childhood survivorship [20]. On this matter, literature [19-20] finds a relationship between education (literacy) and food and nutrition. However, the progressive net enrollment observed between 2000 and 2014 UPE in Uganda was characterized by several constraints which could have curtailed the country's quest of attaining the $100 \%$ universal school enrollment target before December 2015. A range of issues affecting students' abilities to learn and perform particularly in the rural settings have been cited as some of the serious challenges impending UPE progress in Uganda. Food and nutrition deficiency constraints have been at the forefront [21-23]. This is in agreement with a study on how deficiencies of micronutrients such as iodine can lower children's abilities to attend and perform at school, and diminish their chances of completing their education [24].

A great concern, however, is on the low proportion of pupils completing and reaching the last primary grade after enrolling in grade 1 . It was registered at $14.6 \%, 10.7 \%, 6 \%$ and $16 \%$ by 2001, 2005, 2010 and 2015, respectively. In this regard, the unprecedented school drop-outs coupled with late age enrollment and class repetition have been a serious hindrance to achieving MDG 2. To some extent, it is attributable to poverty and limitations on school meals especially in the poverty stricken and rural settings [19, 2123]. These hindrances were observed to lead to regional inequality in primary education like in the case of northern Uganda. For a long time, northern Uganda not only heavily lagged behind in a range of development dimensions, but also in education quality and performance. It was established that poverty, search for food and above all, undernourishment particularly affected orphaned children who took over the role of household head after losing their parents and thus, found it difficult to concentrate in school. It is further reported that some children were forced to work before and after school and oftentimes easily dropped out-of-school [25]. In some cases, school drop-out or failure to finish to last grade to some degree was due to over-age enrollment outside the official primary school age range (6-12 years), caused by poor health and undernourishment during childhood [21]. However, it ought to be noted that other factors oftentimes equally contributed to the rate of school drop-out in Uganda. They include: school distances, disability, early marriage, orphan-hood, parental perception, domestic violence as well as the school environment $[19,21]$.

It is also important to recall that Uganda in the past years was embroiled in civil conflicts in 1970s through 1986 and later in the notorious northern Uganda Lord's Resistance Army conflict. In the midst of this situation, the health service delivery was eroded and disrupted, and like any conflict-affected countries Uganda was hit by a high prevalence of malnutrition and child mortality [26]. Before the MDG were established in 2000 the U5MR and IMR rates were high as noticed in figure 1 although even in the subsequent years the change was not significant. In fact, all along both U5MR and IMR, respectively exceeded the global average rate of 49 and 46 per 1000 live births between 1990 and 2013, respectively [27]. This to some degree shows that Uganda was faced with chronic malnutrition. To counteract the situation, a significant number of nutrition responses were put in place and the most current ones are mainstreamed in the Food and Nutrition Bill 2009 and the broad strategies enveloped in the UNAP 2011-2016 [14, 28]. The two frameworks entail measures aimed at redressing nutrition related challenges. For 
example, they stipulate measures such as nutrition advocacy, maternal, infant and young child feeding and nutrition practices. Others are micronutrient supplementation; access to and consumption to diversified foods; and cost effective nutrition programmes. Nevertheless, the U5MR and IMR in Uganda are still worrying and so far no convincing progress was achieved past the MDG deadline.

The MDG 4 goal aimed at reducing on both U5MR and IMR by two-thirds between 1990 and 2015. This translated into 90 per 1,000 live births and 30 per 1,000 live births, respectively $[27,29]$. However, the reported level of 90 per 1,000 live births and 54 per 1,000 live births for U5MR and IMR, respectively [30] invokes a big concern. It is about whether Uganda can still make any substantial progress towards MDG 4.1 and 4.2 targets in line with the recently adopted Post-2015 Development Agenda. What deserves to be known is that U5MR and IMR in Uganda are attributed to a number of cross-cutting factors. It is undeniable that infections emerging out of malnutrition contribute to U5MR and IMR. In 2000, for instance, diarrhea was reported to lead to IMR and U5MR at $0.2 \%$ and $12.2 \%$, respectively [29]. The nutrition-attributable rate of anemia of $10 \%$ was cited to contribute to both U5MR and IMR [31]. Although the deadline of achieving MDG already passed, it was noted that more concerted measures of reducing U5MR and IMR through vaccination and immunization should be deliberated on and strengthened. A lesson in this regard should be borrowed from the poor progress Uganda recorded in reducing both the U5MR and IMR in the late 1990s and early 2000 in part due to a decline in vaccination coverage [32].

\section{LIMITATIONS}

Although the data which led to results in figure 1 were rigorously cross-checked from varying sources to ensure that they were consistent, unfortunately in some instances the published figures differed. To some extent this poses a great concern on the validity and reliability of the data which is analyzed in this paper although they were retrieved from the authenticated sources.

\section{CONCLUSION}

Before the already passed deadline of achieving the MDG, Uganda only achieved MDG 1.1 of halving the population living below $\$ 1.25$ per day. To some extent, it disapproved the pessimists who argued that LMICs would not be able to achieve any of the MDG goals. By lowering poverty, improving job creation and income generation and saving, other opportunities which are catalysts of human development and socioeconomic wellbeing were boosted. These successes no doubt to some extent enabled the people to improve their socioeconomic status as well as food and feeding practices which in turn reduced the under-five underweight, U5MR and IMR. At the same time, they reinvigorated pupils' effective learning and intellectual capacity. The paper ends by observing that, the newly adopted Post-2015 Development Agenda to which majority of MDG are retrofitted renders Uganda another great opportunity to achieve more MDG targets beyond the MDG 1.1 and nutrition-related ones. However, this should be premised on assessing previous pluses and minuses which blocked the country from achieving a considerable majority of the already elapsed MDG. 


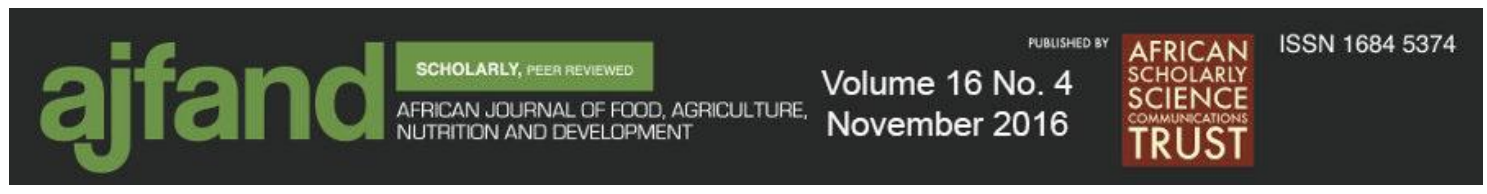

Table 1: Selected indicators for measuring progress of Nutrition Related Millennium Development Goals (1, 2 and 4) and their progress between 2001 and 2014 in Uganda

\begin{tabular}{|c|c|c|c|}
\hline Goal & Millennium Development Goal Indicator & Progress in 2001 & Progress in 2014 \\
\hline \multirow[t]{2}{*}{ MDG 1} & 1.1 Population living below $\$ 1.25$ (PPP) Per day (\%) & $33.8 \%$ & $25.0 \%$ \\
\hline & 1.8 Underweight children under 5 years of age $(\%)$ & $22.8 \%$ & $15.9 \%$ \\
\hline \multirow[t]{2}{*}{ MDG 2} & $\begin{array}{l}\text { 2.1 Net enrollment of both boys and girls in primary } \\
\text { education }(\%)\end{array}$ & $50.9 \%$ & $90 \%$ \\
\hline & $\begin{array}{l}\text { 2.2 Proportion of pupils starting grade } 1 \text { up to last primary } \\
\text { grade }\end{array}$ & $14.6 \%$ & $16 \%$ \\
\hline \multirow[t]{2}{*}{ MDG 4} & $\begin{array}{l}\text { 4.1 Under } 5 \text { child mortality rate (U5MR) per 1,000 live } \\
\text { births }\end{array}$ & 152 per 1,000 live births & 90 per 1,000 live births \\
\hline & 4.2 Infant mortality rate (IMR) per 1,000 live births & 88 per 1,000 live births & 54 per 1,000 live births \\
\hline
\end{tabular}




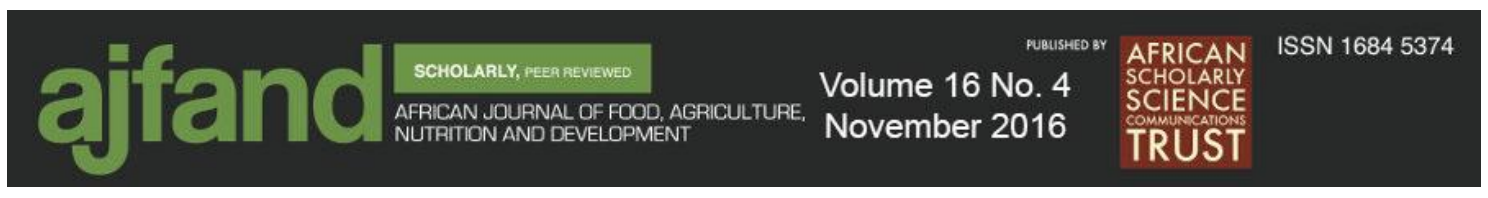

\section{REFERENCES}

1. United Nations. Roadmap towards the implementation of the United Nations Millennium Declaration. UNSG Report, A/56/326. New York, 2001.

2. United Nations. Millennium Declaration Resolution (A/55/L.2) adopted by the United Nations General Assembly on $18^{\text {th }}$ September 2000. New York, 2000.

3. United Nations. The Eight Millennium Development Goals. New York, 2000. Retrievable on: http://www.un.org/millemiumgoals/ (Accessed between April $15^{\text {th }}$ and $30^{\text {th }}$ May, 2015).

4. David H The Millennium Development Goals (MDG). A Short History of the World's Biggest Promise. BWPI Working Paper No. 100. University of Manchester; 2009.

5. United Nations. The Post-2015 Development Agenda. http://www.undp.org/content/undp/en/home/mdgoverview/mdg_goals/post2015-development-agenda.html (Retrieved between $1^{\text {st }}$ and $30^{\text {th }}$, May 2015).

6. William E How the Millennium Development Goals are Unfair to Africa. World Development. 2009; 37 (1): 26-35.

7. Michael $\mathbf{C}$ and $\mathbf{M}$ Todd What's wrong with the Millennium Development Goals? CGD Working Paper No. 40, 2004.

8. Maria K Budget Speech Financial Year 2013/14: The Journey Continues: Towards Socio-Economic Transformation for Uganda. June $13^{\text {th }}$ 2013. Kampala, 2013.

9. United Nations Development Programme. Human Development Report 2014. Sustaining Human Progress: Reducing Vulnerabilities and Building Resilience. New York, 2014.

10. Global Nutrition Report. Actions and Accountability to Accelerate the World's Progress on Nutrition. International Food Policy Research Institute, 2014.

11. Xiaojun W and T Kiyoshi Does Better Nutrition Cause Economic Growth? The Efficiency Cost of Hunger Revisited. FAO, Rome. 2002.

12. United Nations Standing Committee on Nutrition. $6^{\text {th }}$ Report on the World Nutrition Situation 2005. Washington, 2005.

13. The Global Nutrition Report 2014. Actions and Accountability to Accelerate the World's Progress on Nutrition. Washington, 2014.

14. Government of Uganda. Uganda Nutrition Action Plan 2011 - 2016: Scaling up Multi-Sectoral Efforts to Establish a Strong Nutrition Foundation for Uganda's Development. 2011, Kampala. 


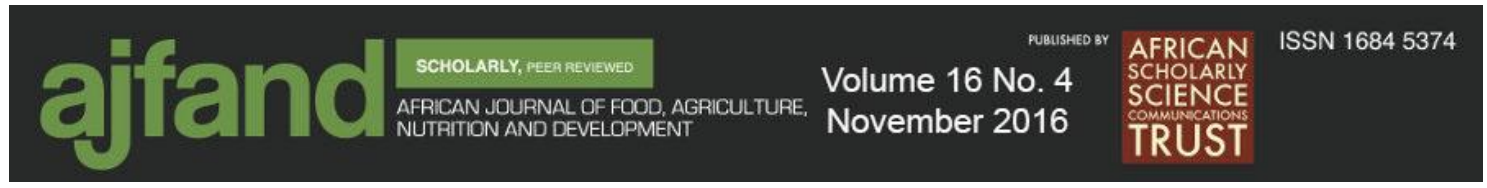

15. Food and Agriculture Organization. The Contribution of Nutrition to Achieving the Millennium Development Goals. FAO's Nutrition and Consumer Protection Division. Rome, 2010.

16. National Planning Authority. National Development Plan 2000/1 - 2014/15. Kampala, Uganda.

17. Government of Uganda. Poverty Eradication Action Plan (PEAP) 2004/5 2007/8. Kampala, Uganda.

18. United Nations. The Millennium Development Goals Report 2014. New York, 2014.

19. Mbabazi C, Awich EO, Olowo EO and YM Lubaale Out of School Children Study in Uganda. Republic of Uganda, 2014.

20. Mukunya D, Kizito S, Orach T, Ndagire R, Tumwakire E, Rukundo G Z, Mupere E and S Kiguli Knowledge of integrated management of childhood illnesses community and family practices (C-IMCI) and association with child under-nutrition in Northern Uganda: a cross-sectional study. BMC Public Health. 2014; 14(976).

21. Tamusuza A Leaving School Early: The quest for Universal Primary Education in Uganda. Journal Statistique Africain. 2011; 13:110-151.

22. Acham H, Kikafunda JK, Malde M K, Oldewage T and A Egal Breakfast, midday meals and academic achievement in rural primary schools in Uganda: implications for education and school health policy. Food and Nutrition Research. 2012; 56(10): 3402.

23. Acham H, Kikafunda J K, Tylleskar T and MK Malde Nutrition and Health Status of Primary School Children in Rural Uganda. AJFAND. 2012; 12(2): 58625880 .

24. Nutrition and the MDG Accelerating progress towards 2015. United Nations Standing Committee on Nutrition. Washington, USA.

25. Kate $\mathbf{H}$ Regional Inequality and Primary Education in Northern Uganda. Policy Brief No 2, Overseas Development Institute, 2009.

26. Nuwaha F and A Mukulu Trends in under-five mortality in Uganda 1954-2000: can Millennium Development Goals be met? African Health Sci. 2009 Jun; 9(2): $125-128$.

27. World Health Organization. New data show child mortality rates falling faster than ever.

http://www.who.int/mediacentre/news/releases/2014/child_mortality_estimates/en/ (Accessed between $15^{\text {th }}$ April and $30^{\text {th }}$ May 2015). 


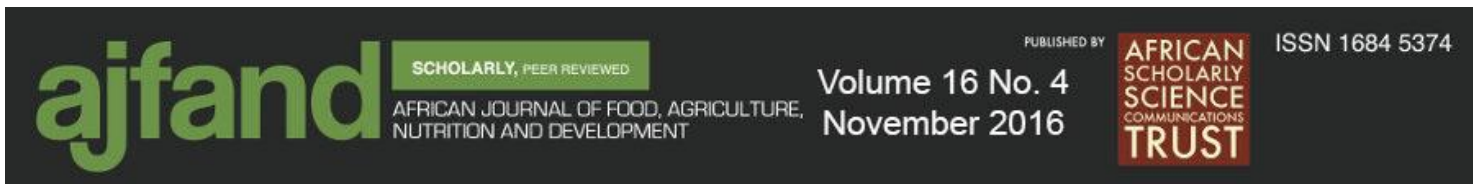

28. Government of Republic of Uganda. Food and Nutrition Bill 2009. Kampala, Uganda 2010.

29. United Nations Children Fund. Under-Five Infant Mortality Rates and Number of Deaths. http://data.unicef.org/child-mortality/under-five (Accessed between 15th April and 30 $0^{\text {th }}$ May 2015).

30. Government of Uganda. Millennium Development Goals Report for Uganda 2013. Kampala, Uganda, 2013.

31. Ssewanya $\mathbf{S}$ and $\mathbf{S}$ Younger Infant Mortality rates in Uganda: Determinants, trends and Millennium Development Goals. Journal of African Economies, 2008; 17(1): $34-61$.

32. Niringiye A Infant mortality rates and decentralization in Uganda. Australian Medical Journal 2015; 8(5): 47-51. 